\title{
Global range expansion of pest Lepidoptera requires socially acceptable solutions
}

\author{
D. M. Suckling $(\mathbb{D} \cdot$ D. E. Conlong $\cdot$ J. E. Carpenter $\cdot$ K. A. Bloem $\cdot$ P. Rendon • \\ M. J. B. Vreysen
}

Received: 13 July 2016/ Accepted: 7 November 2016/Published online: 29 November 2016

(C) The Author(s) 2016. This article is published with open access at Springerlink.com

\begin{abstract}
Caterpillars of key moth pests can cause significant losses in cropping systems worldwide, and globalization is spreading such pests. Failure to control some species can jeopardise the economics of food production. A Global Eradication and Response Database (http://b3.net.nz/gerda) was reviewed on known government-level incursion response programs specific to invasive Lepidoptera. Geographic range expansion of Lepidoptera was evident from 144 incursion response programs targeting 28 species in 10 families. The countries involved in
\end{abstract}

J. E. Carpenter: Retired, formerly USDA-Agricultural Research Service.

D. M. Suckling ( $₫)$

The New Zealand Institute for Plant and Food Research Limited, PB 4704, Christchurch, New Zealand e-mail: max.suckling@plantandfood.co.nz

D. M. Suckling

School of Biological Sciences, University of Auckland, Auckland, New Zealand

\section{M. Suckling}

Better Border Biosecurity, Lincoln, New Zealand

D. E. Conlong

South African Sugarcane Research Institute, 170 Flanders

Drive, Mount Edgecombe, South Africa

D. E. Conlong

School of Life Sciences, University of KwaZulu-Natal, Private Bag X01, Scottsville, Pietermaritzburg 3201, South Africa responses to Lepidoptera were USA (104), Australia (8), Canada (7), New Zealand (6), Italy (3), Mexico (2), with the remainder with one programme each (Brazil, Czech Republic, France, Hungary, and Spain). Most programs have been undertaken since the 1990's. Control options exist for the long-term management of Lepidoptera, but most have issues of cost, efficacy or non-target impacts that reduce their acceptance. Pheromone-based technologies are increasingly available and are generally highly compatible with other tactics. The development of tactics for new targets is a major undertaking, although previous programs can be invaluable. New and improved

\author{
J. E. Carpenter \\ Tifton, GA, USA \\ K. A. Bloem \\ USDA-APHIS-PPQ-Center for Plant Health Science and \\ Technology, 1730 Varsity Dr., Raleigh, NC 27606, USA \\ P. Rendon \\ IAEA Technical Cooperation, Latin América (TCLA), \\ Vienna, Austria \\ P. Rendon \\ 4a. Ave. 12-62, Zona 10, Guatemala City, Guatemala \\ M. J. B. Vreysen \\ Joint FAO/IAEA Programme of Nuclear Techniques in \\ Food and Agriculture, Insect Pest Control Laboratory, \\ PO Box 100, Wagramer-strasse 5, 1400 Vienna, Austria
}


socially-acceptable technologies are needed to counteract range expansion in Lepidoptera, and usually need to be used in combinations to achieve eradication. The sterile insect technique, which involves mass-rearing and release of sterile insects to reduce wild populations of the pest, has been used successfully against a number of lepidopteran species. Several sterile moth programs are under development. New technologies must have a social license to operate in urban areas, where new incursions are frequently detected. This factor is likely to reduce tactical flexibility and increase the complexity of insect eradication.

Keywords Lepidoptera I IPM - Eradication · Suppression $\cdot$ Tactic $\cdot$ Sterile $\cdot$ Pheromone

\section{Introduction}

In the past decade, numerous invasive insect pest species have emerged and continue to emerge as a threat to food production and ecosystem health as a consequence of global trade and climate change (Levine and D'Antonio 2003; Liebhold et al. 2016). Lepidoptera include key insect pests that require control to avoid significant losses in many cropping systems in temperate, sub-tropical and tropical regions of the world (Vreysen et al. 2016). Failure to control these species can have serious consequences for the economics of production, including failure of the crop worldwide (Vreysen et al. 2007). Like other arthropod pests, many Lepidoptera are undergoing geographical range expansion (Lopez-Vaamonde et al. 2010). Some pests, such as diamondback moth, Plutella xylostella L. (Lepidoptera: Plutellidae) have already become ubiquitous global pests. Many moth pests are still undergoing geographic range expansion. A recent European review reported that 97 non-native Lepidoptera species in 20 families have established so far in Europe and 88 European species in 25 families have expanded their range within Europe, with $74 \%$ established during the 20th century (Lopez-Vaamonde et al. 2010). As part of a project identifying factors affecting outcomes from arthropod eradication efforts (Liebhold et al. 2016; Tobin et al. 2014), a global eradication database called "GERDA" (Kean et al. 2016) has recorded 28 lepidopteran species that were the target of 144 known government-led incursion responses (Table 1; Fig. 1), with effort spread across 12 moth families, dominated by the Lymantriinae and Tortricidae. The data, scope and definitions used in the database are available (www.b3nz.org/gerda), reviewed here for Lepidoptera. Government-led incursion response programs, usually targeting eradication, represent a high decision threshold for entry due to cost, and normally mean that a risk analysis has been conducted to assess whether the establishment of the unwanted organism is likely to exceed an economic, environmental or social impact threshold (Tobin et al. 2014). Assembly of the developing data set of responses to invasive Lepidoptera is therefore proposed as a guide to trends in this key threat group, since such response programs are typically multimillion dollar in size (range US\$ 2-94 M in non $\mathrm{Ly}$ mantria programs, normalised to 2012).

For European gypsy moth Lymantria dispar dispar (L), there is a large history of government responses (particularly since 1980), comprising 66\% of entries in GERDA which can be analysed separately (Fig. 1). It is evident that a recent expansion of responses has occurred for other species (10 cases from 1900 to 1990, and 33 responses arising since 1990, Fig. 1). The countries involved in responses to all Lepidoptera incursions were USA (104), Australia (8), Canada (7), New Zealand (6), Italy (3), Mexico (2), with the remainder with one programme each (Brazil, Czech Republic, France, Hungary and Spain).

A total of 42 non-lymantriin eradication programs recorded in GERDA include species such as the tomato leafminer, Tuta absoluta (Meyrick) (Lepidoptera: Gelechiidae), a key and expanding threat to tomato production in the Mediterranean, reported in 2016 by EPPO as detected or transient and under eradication (UK, Austria, Czech Republic, https://gd. eppo.int/taxon/GNORAB/distribution). Likewise, the old world bollworm, Helicoverpa armigera (Hubner) (Lepidoptera: Noctuidae), a severe pest of cotton, has recently been detected in South American and Caribbean countries (EPPO Global Database, https://gd. eppo.int). The European grapevine moth, Lobesia botrana Denis \& Schiffermüller (Lepidoptera: Torticidae) has been detected in the USA and Chile (Gilligan et al. 2011) and affects grapevine production in many Mediterranean countries. The light brown apple moth, Epiphyas postvittana (Walker) (Lepidoptera: Torticidae), a polyphagous horticultural leafroller pest 
Table 1 Cases of 144 incursion responses against 28 species in 12 families of Lepidoptera, recorded in the global Eradication Database (GERDA, http://b3.net.nz/gerda, with indications of dose response or sterile insect field release (seven species))

\begin{tabular}{|c|c|c|c|}
\hline Moth species & Common name & Family & No. of reported incursions \\
\hline Lymantria dispar dispar ${ }^{\mathrm{a}, \mathrm{b}}$ & European gypsy moth & Lymantriinae & 78 \\
\hline Lymantria dispar asiatica $^{\mathrm{a}}$ & Asian gypsy moth & Lymantriinae & 18 \\
\hline Cydia pomonella $a^{\mathrm{a}, \mathrm{b}}$ & Codling moth & Tortricidae & 9 \\
\hline Paysandisia archon & Palm moth & Castniidae & 4 \\
\hline Epiphyas postvittana ${ }^{\mathrm{a}, \mathrm{b}}$ & Light brown apple moth & Tortricidae & 4 \\
\hline Duponchelia fovealis & European pepper moth & Pyralidae & 3 \\
\hline Tuta absoluta ${ }^{\mathrm{a}}$ & Tomato leafminer & Gelechiidae & 2 \\
\hline Euproctis chrysorrhoea & Brown-tail moth & Lymantriinae & 2 \\
\hline Helicoverpa armigera ${ }^{\mathrm{a}}$ & Old world bollworm & Noctuidae & 2 \\
\hline Thaumetopoea pityocampa ${ }^{\mathrm{a}}$ & Pine processionary moth & Notodontidae & 2 \\
\hline Thaumetopoea processionea ${ }^{\mathrm{a}}$ & Oak processionary moth & Notodontidae & 2 \\
\hline 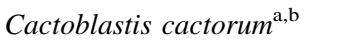 & Cactus moth & Pyralidae & 2 \\
\hline Lobesia botrana ${ }^{\mathrm{a}, \mathrm{b}}$ & European grapevine moth & Tortricidae & 2 \\
\hline 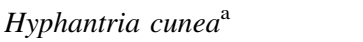 & Fall webworm & Arctiidae & 1 \\
\hline Ostrinia nubilalis ${ }^{\mathrm{b}}$ & European corn borer & Crambidae & 1 \\
\hline Pectinophora gossypiella ${ }^{\mathrm{a}, \mathrm{b}}$ & Pink bollworm & Gelechiidae & 1 \\
\hline Conopomorpha cramerella & Cocoa pod borer, cocoa moth & Gracillariidae & 1 \\
\hline Spulerina isonoma & Mango stem miner & Gracillariidae & 1 \\
\hline Dendrolimus pini & Pine tree lappet moth & Lasiocampidae & 1 \\
\hline Lymantria umbrosa & Hokkaido gypsy moth, dosanko gypsy moth & Lymantriinae & 1 \\
\hline Orgyia thyellina & White spotted tussock moth & Lymantriinae & 1 \\
\hline Teia anartoides ${ }^{\mathrm{a}, \mathrm{b}}$ & Painted apple moth & Lymantriinae & 1 \\
\hline Spodoptera litura ${ }^{\mathrm{a}}$ & Tropical armyworm & Noctuidae & 1 \\
\hline Uraba lugens & Gum-leaf skeletoniser & Noctuidae & 1 \\
\hline Pieris brassicae ${ }^{\mathrm{a}}$ & Large white cabbage butterfly & Pieridae & 1 \\
\hline Citripestis eutraphera & Mango fruit borer & Pyralidae & 1 \\
\hline Opogona sacchari & Banana moth & Tineidae & 1 \\
\hline Grapholita molesta $^{\mathrm{a}}$ & Oriental fruit moth & Tortricidae & 1 \\
\hline Total & & & 144 \\
\hline
\end{tabular}

${ }^{a}$ Dosimetry recorded by the Joint FAO/IAEA Programme of Nuclear Techniques in Food and Agriculture (http://nucleus.iaea.org/ ididas/TaxonomicTree.aspx)

${ }^{b}$ Field releases have been undertaken on these species ${ }^{15}$

has recently spread in California (Suckling et al. 2014a), while the cactus moth, Cactoblastis cactorum Berg (Lepidoptera: Pyralidae) is spreading in the southern USA towards Mexico (Hight et al. 2002), where it threatens endemic and valued cacti (Bloem et al. 2007a). The spotted sugarcane borer, Chilo sacchariphagus Bojer (Lepidoptera: Crambidae) is locally spreading along the eastern coast of Africa in Mozambique, and is present in the Indian Ocean islands of La Réunion, Madagascar and Mauritius
(Conlong and Way 2015). The African sugarcane stalk borer, Eldana saccharina Walker (Lepidoptera: Pyralidae) is reported as difficult to control in maize in West African countries, and in sugarcane in South Africa, Zimbabwe, Tanzania and Uganda (Assefa et al. 2006; Conlong and Way 2015). These cases are a mixture of introductions and regional spread, and illustrate global and regional scales of range expansion and do not always involve eradication responses which depend on the jurisdiction and geolocation. 


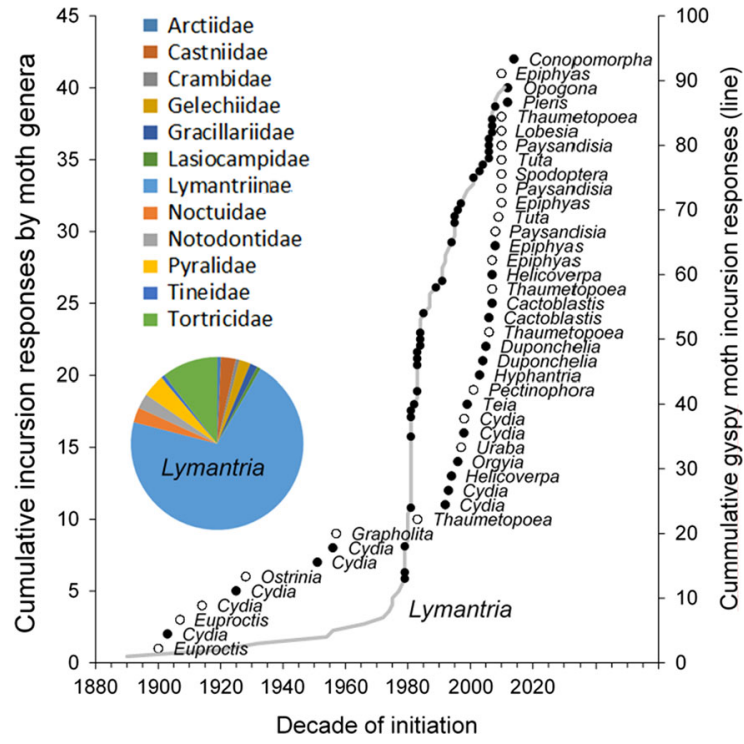

Fig. 1 Commencement dates of government incursion responses to Lepidoptera by decade, for gypsy moths (Lymantria, grey line), compared with other genera of Lepidoptera (filled circles indicate successful eradications, opened circles are failures or ongoing). Pie chart shows distribution by family

\section{Analysis of control options for Lepidoptera}

There is broad international consensus that the management of these key pests is ideally based on the concept of area-wide integrated pest management (AW-IPM) (Klassen 2005), i.e., control tactics should be integrated based on their suitability for a given pest and local ecological characteristics, and the control tactics should be targeting an entire insect population (total population control). Lepidopteran pests have been predominantly managed for decades by application of broad-spectrum and often persistent insecticides, but a wider range of classes of insecticides is potentially available today for use in eradication (Bloem et al. 2014). This management approach has enormous direct and indirect economic, social and environmental consequences and is considered unsustainable in the long term as many lepidopteran pest species have developed resistance to insecticides, including more benign low hazard materials, although this risk may be overstated (Sparks et al. 2012). Many effective but older broad-spectrum insecticides are being phased out in use, due to increased recognition of the long-term effects of their excessive use on human health and the environment. Finally, there is increasing market pressure to reduce insecticide residues on food.

Each suppression tactic that can be used to manage these lepidopteran pests has advantages but also limitations, e.g. some have issues of cost or efficacy, justifying a search for alternatives. Others may be inversely-density dependent and require a population knockdown before they are practical. In addition, usage during an eradication programme in urban environments may also face different acceptability from agriculture (Suckling et al. 2014b). For example, while insecticides are widely used in agriculture, their aerial use during an eradication or even suppression campaign in urban areas can be problematic.

The use of sex pheromones remains an ideal tactic for the management of invasive Lepidoptera, more than for any other group of insects, as there are so many leads already developed in the pest management literature, and the same targets are often invasive (Suckling 2015). Mass trapping and lure and kill options rely on a supply of the attractant (El-Sayed et al. 2006), which is more likely for known pests than novel invasives. Mating disruption can be effective where the technology has been developed, but is comparatively expensive, labor intensive, has issues with edge effects/topography in relation to efficacy, and is most widely adopted in horticulture in developed countries (Witzgall et al. 2010). However, mating disruption has been used in eradication programs against five species/subspecies of Lepidoptera (Lance et al. 2016; Suckling 2015). There are emerging versatile semiochemical technologies with formulations for aerial or ground application, enabling rapid development in future (Brockerhoff et al. 2012; Lance et al. 2016; Mafra-Neto et al. 2014).

Classical biological control using egg or larval parasitoids has been widely investigated for the management of many invasive insect pests (Gurr and Wratten 2000), but is usually inadequate alone in suppressing the pest below the economic threshold. The host species specificity of natural enemies on Lepidoptera needs to be demonstrated before release to avoid possible negative impacts on non-target arthropod species, or to avoid establishment of the parasitoid becoming a pest themselves (Munro and Henderson 2002). Biopesticides such as Bacillus thuringiensis kurstaki and baculoviruses can be made effective for some pests, although commercial availability, cost, efficacy and the evolution of resistance 
can be problematic (Glare and O'Callaghan 2000; Tabashnik et al. 2012). Cultural controls such as sanitation can also be used as part of integrated pest management approaches where intensive field surveys may occur (Stephens et al. 2007), although sanitation or host removal is only considered effective when integrated with other control tactics.

The sterile insect technique (SIT) has been used successfully against moth pests by mass-rearing and release of sterile insects to overflood the wild population (Vreysen et al. 2016). The ongoing area-wide suppression of codling moth in apple and pear orchards of the Okanagan Valley of British Columbia, Canada has used the SIT along with other tactics (Bloem et al. 2007b) and there is potential to expand this approach for pest management in Canada, Europe, New Zealand, South Africa, and South America. Field trials commenced in New Zealand in 2014 involving the release of sterile Canadian codling moths in combination with mating disruption (Horner et al. 2016), where the target is market access, in a pilot program testing the potential for local eradication.

An AW-IPM suppression approach that integrates the SIT has also been successful in the private sector management of the false codling moth, Thaumatotibia (Cryptophlebia) leucotreta (Meyrick) (Lepidoptera: Tortricidae) in South African citrus orchards (Carpenter et al. 2007; Hofmeyr et al. 2015) (http://www. xsit.co.za). Small scale releases of sterile Lobesia botrana were planned by the government in Santiago, Chile in September 2016 (H. Donoso pers. comm.) and were also conducted in Los Angeles by USDA APHIS with sterile E. postvittana (G. Simmons pers. comm).

While concepts and technologies of SIT for one species can often provide a basis for developing methods for another species, technology development and adaptation is needed each time a new species is targeted. Even within a species, scaling up from pilot to operational, or simply moving into a new rearing facility, can generate problems that have to be solved. The SIT acts with inverse density dependence, and becomes therefore more efficient with lower densities of the target population. The most effective approach therefore, is to combine the SIT with control tactics that are more effective at high population densitiesthe ideal efficiency pattern in AW-IPM strategies. In addition, the SIT combines well with other control tactics such as parasitoids and the combination can even be synergistic where tactics interact positively
(Suckling et al. 2012). Bi-sex sterile moth releases and egg parasitoid inundation may exhibit greater complementarity than other combinations of methods, since their optimal action is at opposite ends of the host density spectrum and they do not in any way interfere with each other unless adult hosts are parasitized (Barclay 1987). Genetic modification can target marking or sterility of Lepidoptera, which could accelerate response and eradication outcomes (Simmons et al. 2007; Thomas et al. 2000).

\section{Combinations of tactics}

The integration of area wide tactics has been successfully used for the suppression, containment and eradication of moth pest populations (Bloem et al. 2005), but the small number of moth eradication programs means that information gained from long term pest management programs should not be overlooked. Strategies for integration of tactics vary between insect orders (Suckling et al. 2014b), although there are several socially-acceptable tactical options for Lepidoptera under development, which have been combined in various ways to target suppression of either gypsy moth or other moth species. Many different combinations have been used against gypsy moth and other pests, sometimes successful but other times not, but with an improving success rate over time if the ongoing cases are removed (Fig. 1). The use of more tactics has generally produced more success (Fig. 2), according to a two way ANOVA for success in Lymantria and nonLymantria cases $\left(\mathrm{F}_{3,1,3}=9.62\right.$ and $P<0.05$ for number of tools and $\mathrm{F}_{3,1,3}=7.19$ and $P=0.08$ for

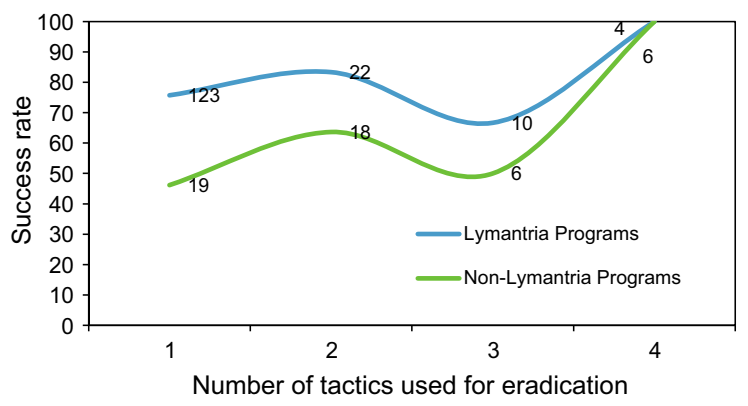

Fig. 2 Effect of tactical combinations on eradication success in Lymantria and other Lepidoptera (numbers are the sample size of known programs). Source www.b3nz.org/gerda 
moth type). The main tactics identified in previous programs against Lepidoptera include pesticides and biopesticides, host removal, sterile insect release and pheromone-based tactics (mating disruption, lure and kill and mass trapping). However, an additional component to consider is the time taken for the development of each tactic and the steps needed for implementation (Fig. 3), which may need to take place during an emergency response. A ranking and comparison of what is involved in the development of these tactics for new targets is generalised from the example of the painted apple moth eradication in Auckland (Suckling et al. 2007). For codling moth, most of the recorded eradications were in Western Australia, and generally involved host destruction, requiring several years.

Undoubtedly, the most impressive example of the integrated approach is the eradication of the pink bollworm, Pectinophora gossypiella Saunders (Lepidoptera: Gelechiidae) from the southern USA and northern Mexico using an AW-IPM approach that combined Bt cotton, sterile insect release and mating disruption (Tabashnik et al. 2012). Other examples of successful AW-IPM programs that included a SIT/IS component include the eradication of the Australian painted apple moth, Teia anartoides Walker (Lepidoptera: Lymantriinae) from urban Auckland, New Zealand (Suckling et al. 2007) and C. cactorum from Isla Mujeres and Isla Contoy in Mexico (Bloem et al. 2007a). Clearly, despite several successful cases, the technology is contributing below its potential in an area with an expanding challenge for global food security. A diagram illustrates a simplified decision tree for use of SIT based on essential components (Fig. 4). The remainder of this article will focus on sterility in Lepidoptera, as this technology has much potential for use in suppression or eradication strategies, especially in combination with sex pheromones, biopesticides and other tactics (Carpenter et al. 2005).

\section{Sterile with competitive field performance}

Despite the successes of operational field programs and the availability of generally encouraging results from pilot field releases of a range of moth pest species (Table 1), there are remaining issues pertaining to the competitiveness of the released insects that require further investigation to increase the efficacy and cost efficiency of the SIT against lepidopteran pests. Some

STEPS EXPECTED IN A NOVEL LEPIDOPTERAN ERADICATION PROGRAM

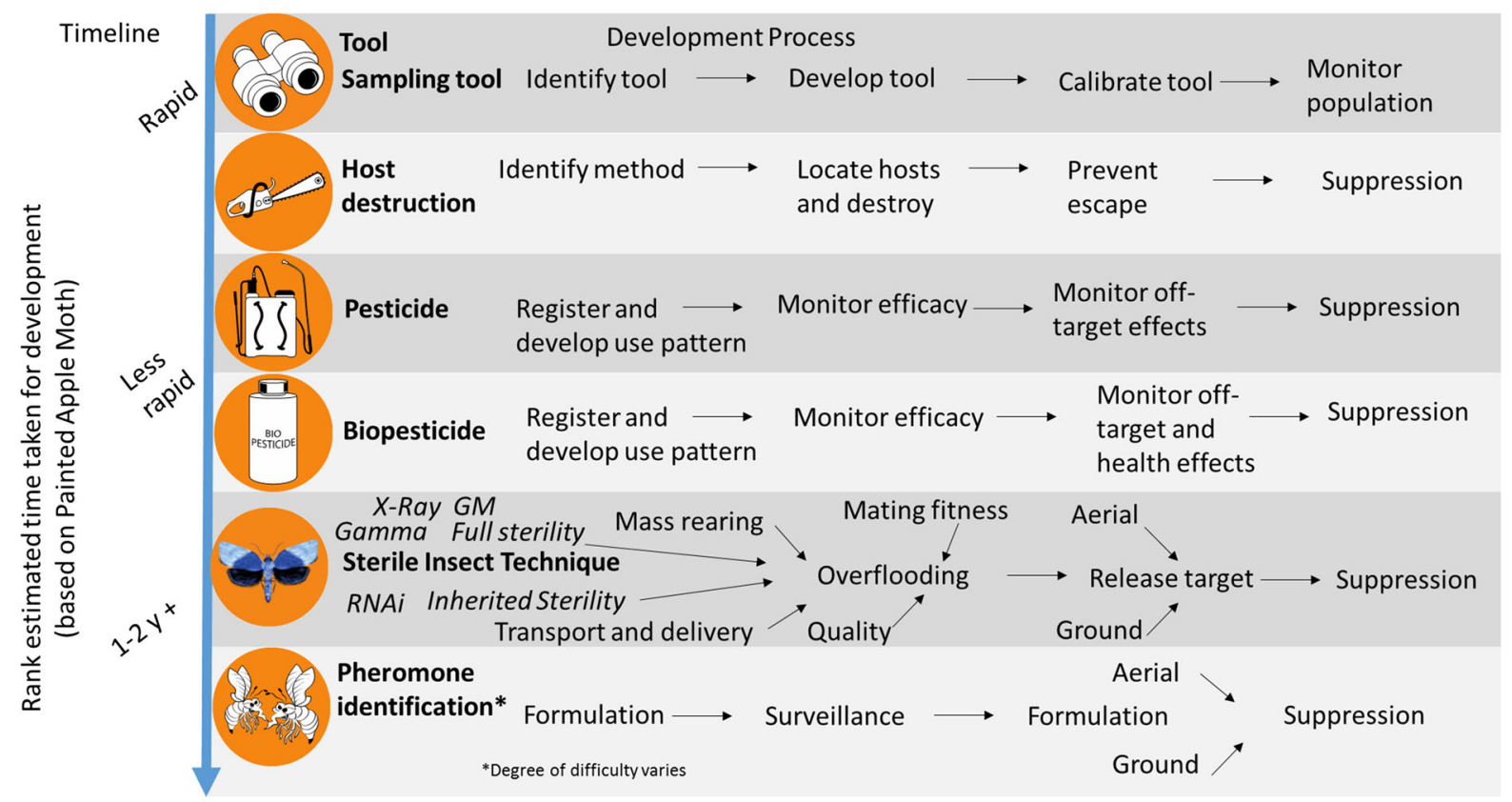

Fig. 3 Schematic diagram of generic steps expected in the potential development of eradication tools for Lepidoptera, based on painted apple moth (Suckling et al. 2007) 
Fig. 4 Decision tree on the suitability of the Sterile Insect Technique for use in an eradication or population reduction program
Decision tree for the Sterile Insect Technique

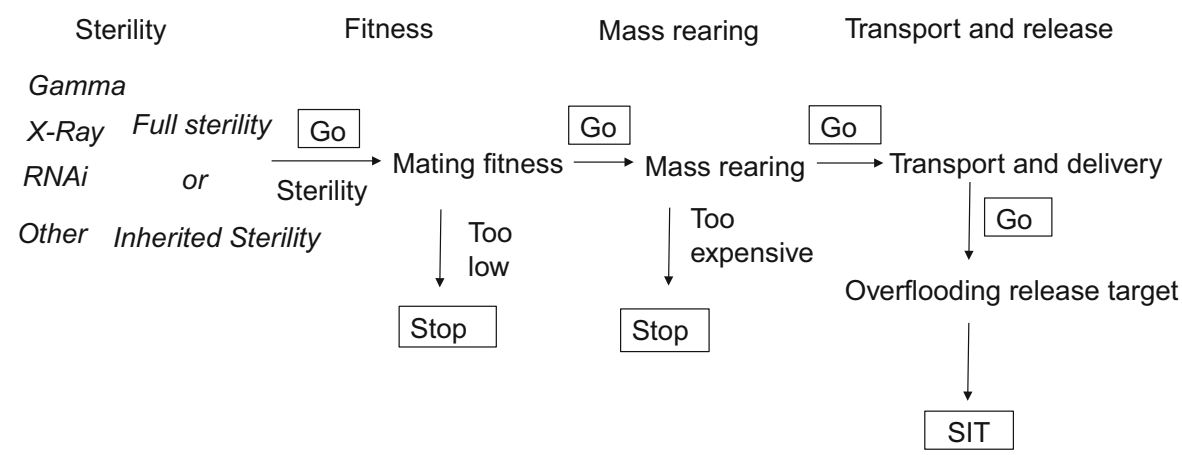

of these critical aspects were addressed in an FAO/ IAEA coordinated research project entitled "Increasing the efficiency of Lepidoptera SIT by enhanced quality control" which was implemented between 2008 and 2014, and reported in a special issue of the Florida Entomologist (Vreysen et al. 2016). The use of the SIT has been limited to only a few operational programs against Lepidoptera for long term pest suppression (codling moth in Canadian apples and false codling moth in South African citrus) or eradication (pink bollworm in US cotton, Australian painted apple moth in urban New Zealand and cactus moth on islands in Mexico) (Bloem et al. 2005) but assessment of moth quality was investigated on a wider range of species (Simmons et al. 2010; Vreysen et al. 2016). The SIT requires mass-rearing and release of sterile insects with competitive field performance, which creates a major threshold for entry through the need for a specialised factory, which is a capital cost hurdle that in part explains the small number of cases (Fig. 4). While there is pre-requisite information on irradiation dose-response effects for many moth pest species, the overall effects are not necessarily sufficiently understood for practical purposes at the program level. There are key factors and variables in the rearing and release processes that affect the quality of the moths and their field performance that need further research and development (Simmons et al. 2010).

\section{Other factors affecting the outcome}

SIT may not be appropriate when there is no artificial diet and rearing system, sterility has too great an impact on fitness or other logistical factors limit the application (Fig. 4). Thus factors other than irradiation can influence the outcome of a programme with a SIT component. Mass-rearing, handling and transport methods all have critical impacts on the quality and performance of insects (Fig. 4), and these are major practical issues requiring more research (Simmons et al. 2010). Insect quality can be gradually degraded during all these processes up to a point where the sterile insects are no longer competitive with wild insects. There are many quality measures showing reduced competitiveness of irradiated insects, which can be used to determine the over-flooding ratio of sterile to wild insects needed. These factors would be just as important for programs using other sources of marking and sterility, from transgenic (Simmons et al. 2011) to RNAi (Schetelig et al. 2012), although this has not always been acknowledged or perhaps understood by proponents of these technologies (Alphey 2000; Knipple 2013). Hence there is a need to link production, handling and transport more closely with behavioral traits, and to select for traits that might improve field performance, such as mating or flight propensity at particular times or temperatures (Sørensen et al. 2012). This can be achieved by introducing selection for desirable traits into rearing procedures, similar to those for maintaining other traits (Fisher and Caceres 2000). Although this can be complex and management intensive to implement in an operational programme, it is likely to increase the probability of technical and financial success, as has been shown with programmes against the Mediterranean fruit fly (McInnis et al. 2002). New genetic methods could be developed to mark fitness traits easily, and maintain appropriate genetic diversity in colonies. 
In Lepidoptera, adult irradiation may give better field performance of sterile males, but can potentially be less practical and more damaging than transport of pupae, which can offer more flexibility for programs (Blomefield et al. 2011; Soopaya et al. 2011; Suckling et al. 2005). Irradiation and shipment of pupae may have logistical and other advantages over shipment of adults depending often on the distance between the mass-rearing site and the target release area, but most programs against Lepidoptera have used adult irradiation to date (Bloem et al. 2005). Some of these programs faced issues of stockpiling insects, synchrony, losses during extended storage, and other tradeoffs. Placement of irradiated pupae to emerge in the field has been done experimentally, but requires adequate protection from predation (Stringer et al. 2013). The Australian painted apple moth program in New Zealand was an operational example using pupal irradiation (Suckling et al. 2007) and this approach was also explored for gypsy moth (Reardon and Mastro 1993). Although not implemented anywhere, adult moths could also be irradiated at satellite emergence and release facilities after pupal shipment (assuming appropriate diets and rearing systems are developed), possibly by X-ray.

\section{Operational strategies}

Despite attempts to model the effects of bi-sex or male-only releases of moths that suggested little benefit from females (Kean et al. 2011), there is evidence for a background contribution of the female moths through communication disruption of males from calling virgin females, despite their irradiationreduced attractiveness and pheromone titre (Stringer et al. 2013; Suckling et al. 2006). Further, it has been suggested that there may be a benefit from sterile females acting as a "sperm sink" for wild males thereby reducing wild male fertility, which could contribute to part of the observed effect of population suppression. Although it remains unclear whether bisex releases are superior to male-only releases of moths, there is no risk of commodity damage from oviposition by sterile female moths, as unlike fruit flies, these species do not pierce the fruit. In fact, oviposition and the production of $F_{1}$ sterile adults is a key component of inherited sterility, and offers several benefits over releases of fully sterile parental individuals (Bloem et al. 2005). In particular, successful sterile males mating a wild female produce a large number of offspring biased towards males (depending on dose) and sterile at $F_{2}$. It may be necessary to take crop damage from $F_{1}$ larvae into account (LaChance 1985), although during an eradication this should be of short duration. In addition, a synergistic benefit of the combination of two tactics has been demonstrated to occur, for example where sterile eggs oviposited by released sterile females have been shown to enhance the numerical response of egg parasitoids (Bloem et al. 1998; Cossentine and Jensen 2000).

As with fruit flies, male-only release of moths might reduce costs, including rearing, handling, shipping and release costs. Currently, the lack of any effective genetic sexing strain in Lepidoptera for production of males alone presents a limitation, although sorting of the sexes at pupal or adult stages might enable release of separate sexes, offering similar benefits. Females can be used for baiting traps, as was done in the painted apple moth eradication program in New Zealand, which used sterile male-only release after manual sorting of larvae (Suckling et al. 2007). Collection of pupae and sorting by sex if possible would reduce or avoid mating before adult collection and release, which represents a source of inefficiency. Sorting options with less than complete separation of sexes might still be practical if significantly skewed sex ratios provided sufficient benefit from male dominant release. Anoxia and other treatments during irradiation could decrease the somatic damage and hence improve sterile moth quality and their field performance. Moths are often irradiated under chilled conditions, and this process needs to be optimized. The impact of temperature shocks during rearing warrants investigation for some species (Chidawanyika and Terblanche 2011). There is also an upper limit to the practical duration of shipping before release $(60-80 \mathrm{~h}$ in the case of irradiated codling moth adults at $0.5^{\circ} \mathrm{C}$ ) (Blomefield et al. 2011; Horner et al. 2016).

Transport and release methods that avoid degradation by physical damage can significantly improve the performance of sterile insects in the field. Ground release of chilled moths that take some time to warm up and fly could lead to significant losses from predation or other sources (Stotter and Terblanche 2009). Negative effects of ground release of chilled 
moths on their quality might be mitigated by aerial release, allowing the insects to warm up, become active and settle into the canopy before reaching the ground.

It remains a challenge to have suitable unbiased standard methods for measuring moth quality at the factory and after transport and handling. This is important for the interpretation of field performance, to understand measures like trap catch. For example, Judd and Gardiner (2006) found that non-irradiated mass-reared codling moths were recaptured about four-fold less often than non-irradiated wild moths released under identical conditions. Potential differences in responses between wild and diet-reared insects could provide a misleading source of feedback on sterile moth performance to program managers, leading to potentially expensive and suboptimal decisions. Laboratory, semi-field and open field methods need to be aligned to help ensure overflooding ratios are adequate, or there is a risk of unwanted population growth despite assumed adequate insect release densities. Other new methods could be used to support field programs, including direct assessment of the frequency of $F_{1}$ sterile progeny by histology (Carpenter et al. 2009) or other methods, although this may require living or freshlydead insects (Wee et al. 2011). Female moth attractants are increasingly emerging as a population sampling and control tool (e.g. El-Sayed et al. 2013; Landolt et al. 2007; Light 2016).

\section{Population modelling for decision support}

Modelling approaches can help field programs with an SIT component by optimizing field deployment of the sterile insects (Barclay et al. 2011; Kean et al. 2011; Potgieter et al. 2013). Deployment strategies can have a large impact on the outcome of sterile insect release programs because of insect aggregation (Kean et al. 2007). Population models suggest that there is a risk of program failure unless over-flooding ratios remain above critical threshold values throughout the target area, including the hotspot, or areas of local high density (Kean et al. 2007). Variance in over-flooding ratios can be minimized by the identification and incorporation of information of the location and density of hotspots along with different crop ages (Potgieter et al. 2013). This problem is amenable to spatially-explicit modelling, to overcome naturally occurring aggregations, by directing releases appropriately to improve efficiency. Combinations of tactics such as the SIT and mating disruption, Bt crops, a heterogeneous agricultural crop landscape (Potgieter et al. 2014) or a range of alternatives, can theoretically lead to more efficient outcomes if the tactics can be made to work together synergistically (Suckling et al. 2012). These approaches can also be modeled to investigate interactions (Blackwood et al. 2012; Kean et al. 2011) and male calling and lek behavior (van Vuuren et al. 2015). Variance in overflooding ratios could potentially be minimized by the identification and incorporation of information of the location and density of hotspots. Other tactical combinations also warrant investigation where eradication is sought, since all methods can help to reduce populations and enable Allee effects to operate best (Liebhold et al. 2016). The use of global positioning and global information systems (GPS/GIS) has introduced considerable improvements in control tactics of fruit flies due to the feasibility of mapping movement of pests, hotspots, reservoirs as well as phenological and physical barriers so its deployment should be a must for Lepidoptera control programs. Additionally, the economic implications of different SIT deployment approaches can be compared taking into account aggregation (Potgieter et al. 2013; Wee et al. 2011).

\section{Conclusions}

Global range expansion is evident in pest Lepidoptera from data (which are undoubtedly incomplete) available so far in GERDA. For gypsy moth, there was an increase in the US response programs to slow-thespread from the 1980s onwards (Sharov et al. 2002). For other Lepidoptera, an increase occurred from the 1990 s, with $75 \%$ of the government response programs established since then (a tenfold increase per decade). Expansion of effort in pest management has no doubt also occurred against aggressive species such as T. absoluta (Desneux et al. 2010), where ranges expansion in Europe has occurred without government response programs targeting eradication.

Eradication and/or effective suppression of Lepidoptera is likely to be more successful when more tactics are available, including pheromone-based tactics, the SIT, biopesticides and other alternative 
options. The development of a range of sociallyacceptable control tactics is much needed to combat the spread of invasive Lepidoptera, including many known pests with potential for increased impacts on food production if established more widely.

However, maintaining the highest quality of insects mass-reared, sterilized and transported for release is crucial to success with counterattacks based on sterile insects, independent of source of sterility. Key areas for further development include determining the relative effectiveness of different methods for quality assessment and performance comparison of sterile and wild moths. This can be done by determining the impact that different rearing performance parameters, rearing practices and behavioral traits have on competitiveness of sterile moths, through correlation of laboratory and semi- and open-field performance (Suckling et al. 2011; Woods et al. 2016). Knowledge is needed on the impact of timing of adult and pupal collection and irradiation on field competitiveness, as well as the role of sterile females on population suppression. Further needs include the development of best practice methods of handling, transporting and releasing sterile moths to maintain field competitiveness, in particular considering the option of long distance shipment. In addition, it would be valuable to develop best practice deployment of sterile insects in relation to hotspots (Kean et al. 2007), taking into account insect quality and performance and spatial variation in density (i.e., determine appropriate and dynamic sterile: wild release ratios for population suppression). It would also be valuable to know more about the type and role of microorganisms/symbionts in Lepidoptera egg and larval development, to improve rearing and handling practices, and potentially lead to new complementary control tactics. Workers in all these fields are encouraged to contribute their knowledge to the development of the SIT and other tactics for invasive species such as those discussed here.

Acknowledgements We thank the Joint FAO/IAEA Division of Nuclear Techniques in Food and Agriculture for funding the consultants meeting that reviewed the status of SIT against Lepidoptera, Better Border Biosecurity (www.b3nz.org), Dr. John Kean of AgResearch for support for the Global Eradication Database and Lloyd Stringer for discussions.

Open Access This article is distributed under the terms of the Creative Commons Attribution 4.0 International License (http:// creativecommons.org/licenses/by/4.0/), which permits unrestricted use, distribution, and reproduction in any medium, provided you give appropriate credit to the original author(s) and the source, provide a link to the Creative Commons license, and indicate if changes were made.

\section{References}

Alphey L (2000) Re-engineering the sterile insect technique. Insect Biochem Mol Biol 32:1243-1247

Assefa Y, Conlong DE, Mitchell A (2006) Status of Eldana saccharina (Lepidoptera: Pyralidae), its host plants and natural enemies in Ethiopia. Bull Entomol Res 96:497-504

Barclay HJ (1987) Models for pest control: complementary effects of periodic releases of sterile pests and parasitoids. Theor Popul Biol 32:76-89. doi:10.1016/00405809(87)90041-4

Barclay HJ, Matlock R, Gilchrist S, Suckling DM, Reyes J, Enkerlin WR, Vreysen MJB (2011) A conceptual model for assessing the minimum size area for an area-wide integrated pest management program. Int J Agron. doi:10. $1155 / 2011 / 409328$

Blackwood JC, Berec L, Yamanaka T, Epanchin-Niell RS, Hastings A, Liebhold AM (2012) Bioeconomic synergy between tactics for insect eradication in the presence of Allee effects. Proc R Soc Biol Sci Ser B 279:2807-2815. doi:10.1098/rspb.2012.0255

Bloem S, Bloem KA, Knight AL (1998) Oviposition by sterile codling moths, Cydia pomonella (Lepidoptera: Tortricidae) and control of wild populations with combined releases of sterile moth and egg parasitoids. J Entomol Soc B C 95:99-109

Bloem KA, Bloem S, Carpenter JE (2005) Impact of moth suppression/eradication programmes using the sterile insect technique or inherited sterility. In: Dyck VA, Hendrichs J, Robinson AS (eds) Sterile insect technique: principles and practice in area-wide integrated pest management. Springer, Dordrecht, pp 677-700

Bloem KA, Bloem S, Carpenter JE, Hight S, Floyd J, Zimmermann H (2007a) Don't let cacto blast us: development of a bi-national plan to stop the spread of the cactus moth Cactoblastis cactorum in North America. In: Vreysen MJB, Robinson AS, Hendrichs J (eds) Area-wide control of insect pests. From research to field implementation. Springer, Dordrecht, pp 337-344

Bloem S, Carpenter JE, McCluskey A, Fugger R, Arthur S, Wood S (2007b) Suppression of the codling moth Cydia pomonella in British Columbia, Canada using an area-wide integrated approach with an SIT component. In: Vreysen MJB, Robinson AS, Hendrichs J (eds) Area-wide control of insect pests: from research to field implementation. Springer, Dordrecht, pp 591-602

Bloem K, Brockerhoff EG, Mastro V, Simmons GS, Sivinski J, Suckling DM (2014) Insect eradication and containment of invasive alien species. In: Gordh G, McKirdy S (eds) The handbook of plant biosecurity. Springer, Netherlands, pp 417-446

Blomefield T, Carpenter JE, Vreysen MJB (2011) Quality of mass-reared codling moths (Lepidoptera: Tortricidae) after 
long-distance transportation: 1. Logistics of shipping procedures and quality parameters as measured in the laboratory. J Econ Entomol 104:814-822

Brockerhoff EB, Suckling DM, Kimberley M et al (2012) Aerial application of pheromones for mating disruption of an invasive moth as a potential eradication tool. PLoS ONE 7(8):e43767. doi:10.1371/journal.pone.0043767

Carpenter JE, Bloem S, Marec F (2005) Inherited sterility in insects. In: Dyck VA, Hendrichs J, Robinson AS (eds) Sterile insect technique: principles and practice in areawide integrated pest management. Springer, Dordrecht, pp 115-146

Carpenter JE, Bloem S, Hofmeyr H (2007) Area-wide control tactics for the false codling moth Thaumatotibia leucotreta in South Africa: a potential invasive species. In: Vreysen MJB, Robinson AS, Hendrichs J (eds) Area-wide control of insect pests: from research to field implementation. Springer, Dordrecht, pp 351-359

Carpenter JE, Marti OG, Wee SL, Suckling DM (2009) Cytological attributes of sperm bundles unique to $F 1$ progeny of irradiated male Lepidoptera: relevance to sterile insect technique programs. Fla Entomol 92:80-86. doi:10.1653/ 024.092 .0113

Chidawanyika F, Terblanche JS (2011) Costs and benefits of thermal acclimation for codling moth, Cydia pomonella (Lepidoptera: Tortricidae): implications for pest control and the sterile insect release programme. Evol Appl 4:534-544

Conlong DE, Way MJ (2015) Sugarcane. In: Prinsloo GL, Uys VM (eds) Insects of cultivated plants and natural pastures in Southern Africa. Entomological Society of Southern Africa, Hatfield, pp 56-176

Cossentine JE, Jensen LBM (2000) Releases of Trichogramma platneri (Hymenoptera: Trichogrammatidae) in apple orchards under a sterile codling moth release program. Biol Control 18:179-186

Desneux N, Wajnberg E, Wyckhuys KAG et al (2010) Biological invasion of European tomato crops by Tuta absoluta: ecology, geographic expansion and prospects for biological control. J Pest Sci 83:197-215. doi:10.1007/ s10340-010-0321-6

El-Sayed A, Suckling D, Wearing C, Byers J (2006) Potential of mass trapping for long-term pest management and eradication of invasive species. J Econ Entomol 99:1550-1564

El-Sayed AM, Lyn C, Revell J, Manning L-A, Knight A, Bus V, Suckling DM (2013) Apple volatiles synergize the response of codling moth to pear ester. J Chem Ecol 39:643-652. doi:10.1007/s10886-013-0277-0

Fisher K, Caceres C (2000) A filter rearing system for mass reared genetic sexing strains of Mediterranean fruit fly (Diptera: Tephritidae). In: Tan K-H (ed) Area-wide control of fruit flies and other insect pests, joint proceedings of the international conference on area-wide control of insect pests and of the fifth international symposium on fruit flies of economic importance, Penang, Malaysia, 1-5 June 1998. Penerbit Universiti Sains Malaysia, Penang, pp 543-550

Gilligan TM, Epstein ME, Passoa SC, Powell JA, Sage OC, Brown JW (2011) Discovery of Lobesia botrana ([Denis \& Schiffermüller]) in California: an invasive species new to
North America (Lepidoptera: Tortricidae). Proc Entomol Soc Wash 113:14-30

Glare TR, O'Callaghan M (2000) Bacillus thuringiensis: biology, ecology and safety. Wiley, Chichester

Gurr G, Wratten SD (2000) Biological control: measures of success. Kluwer Academic Publishers, Boston

Hight SD, Carpenter JE, Bloem KA, Bloem S, Pemberton RW, Stiling P (2002) Expanding geographical range of Cactoblastis cactorum (Lepidoptera: Pyralidae) in North America. Fla Entomol 85(3):527-529

Hofmeyr JH, Carpenter JE, Bloem S, Hofmeyr M, Groenewald SS (2015) Development of the sterile insect technique to suppress false codling moth Thaumatotibia leucotreta (Lepidoptera: Tortricidae) in citrus fruit: research to implementation (part 1). Afr Entomol 23:180-186. doi:10. 4001/003.023.0112

Horner RM, Walker JTS, Rogers DJ, Lo PL, Suckling DM (2016) Use of the sterile insect technique in New Zealand: benefits and constraints. N Z Plant Prot 68:296-304

Judd GJR, Gardiner MGT (2006) Temperature, irradiation and delivery as factors affecting spring-time flight activity and recapture of mass-reared male codling moths released by the Okanagan-Kootenay sterile insect programme. J Entomol Soc B C 103:19-31

Kean JM, Stephens AEA, Wee SL, Suckling DM (2007) Optimizing strategies for eradication of discrete-generation lepidopteran pests using inherited sterility. In: Vreysen MJB, Robinson AS, Hendrichs J (eds) Area-wide control of insect pests: from research to field implementation. Springer, Dordrecht, pp 211-220

Kean JM, Suckling DM, Stringer LD, Woods B (2011) Modeling the sterile insect technique for suppression of light brown apple moth (Lepidoptera: Tortricidae). J Econ Entomol 104:1462-1475

Kean JM, Suckling DM, Sullivan NJ, et al. (2016) Global eradication and response database. http://b3.net.nz/gerda. Accessed 25 Oct 2016

Klassen W (2005) Area-wide integrated pest management and the sterile insect technique. In: Dyck VA, Hendrichs J, Robinson AS (eds) Sterile insect technique: principles and practice in area-wide integrated pest management. Springer, Dordrecht, pp 39-68

Knipple DC (2013) Prospects for the use of transgenic approaches to improve the efficacy of the Sterile Insect Technique (SIT) for control of the codling moth Cydia pomonella Linnaeus (Lepidoptera: Tortricidae). Crop Protect 44:142-146

LaChance LE (1985) Genetic methods for the control of Lepidopteran species. USDA Agric Res Serv 28:1-40

Lance DR, Leonard DS, Mastro VC, Walters ML (2016) Mating disruption as a suppression tactic in programs targeting regulated lepidopteran pests in USA. J Chem Ecol 42:590-605

Landolt PJ, Suckling DM, Judd GJR (2007) Positive interaction of a feeding attractant and a host kairomone for trapping the codling moth, Cydia pomonella (L.). J Chem Ecol 33:2236-2244. doi:10.1007/s10886-007-9391-1

Levine JM, D'Antonio CM (2003) Forecasting biological invasions with increasing international trade. Conserv Biol 17:322-326. doi:10.1046/j.1523-1739.2003.02038.x 
Liebhold AM, Berec L, Brockeroff EG et al (2016) Eradication of invading insect populations: from concepts to applications. Annu Rev Entomol. doi:10.1146/annurev-ento010715-023809

Light DM (2016) Control and monitoring of codling moth (Lepidoptera: Tortricidae) in walnut orchards treated with novel high-load, low-density "meso" dispensers of sex pheromone and pear ester. Environ Entomol 45:700-707. doi:10.1093/ee/nvw017

Lopez-Vaamonde C, Agassiz D, Augustin S et al (2010) Chapter 11: Lepidoptera. BioRisk 4:603-668. doi:10.3897/ biorisk. 4.50

Mafra-Neto A, de Lame FM, Fettig CJ et al (2014) Manipulation of insect behavior with specialized pheromone and lure application technology $\left(\right.$ SPLAT $\left.^{\circledR}\right)$. In: Beck J, Coats J, Duke S, Koivunen M (eds) Natural products for pest management. ACS Publications, Americal Chemical Society, Washington, DC, pp 31-58

McInnis DO, Shelly TE, Komatsu J (2002) Improving male mating competitiveness and survival in the field for medfly, Ceratitis capitata (Diptera: Tephritidae) SIT programs. Genetica 116:117-124. doi:10.1023/a:1020919927542

Munro VMW, Henderson IM (2002) Nontarget effect of entomophagous biocontrol: shared parasitism between native lepidopteran parasitoids and the biocontrol agent Trigonospila brevifacies (Diptera: Tachinidae) in forest habitats. Environ Entomol 31:388-396

Potgieter L, van Vuuren JH, Conlong DE (2013) A reactiondiffusion model for the control of Eldana saccharina Walker in sugarcane using the sterile insect technique. Ecol Model 250:319-328

Potgieter L, van Vuuren JH, Conlong DE, van Vuuren BJ (2014) Optimising sugarcane field layouts for pest control. Proc S Afr Sugar Technol Assoc 87:447-450

Reardon RC, Mastro VC (1993) Development and status of the sterile insect technique for managing gypsy moth. Technical Series NA-TP-13-93. USDA Forest Service, Forest Health Protection, Radnor, PA

Schetelig MF, Milano A, Saccone G, Handler AM (2012) Male only progeny in Anastrepha suspensa by RNAi-induced sex reversion of chromosomal females. Insect Biochem Mol Biol 42:51-57. doi:10.1016/j.ibmb.2011.10.007

Sharov AA, Leonard D, Liebhold AM, Roberts EA, Dickerson W (2002) "Slow the spread": a national program to contain the gypsy moth. J For 100:30-35

Simmons GS, Alphey LS, Vasquez T, Morrison NI, Epton MJ, Miller E, Miller TA, Staten RT (2007) Potential use of a conditional lethal transgenic pink bollworm Pectinophora gossypiella in area-wide eradication or suppression programmes. In: Vreysen MJB, Robinson AS, Hendrichs J (eds) Area-wide control of insect pests: from research to field implementation. Springer, Dordrecht, pp 119-124

Simmons GS, Suckling DM, Carpenter JE, Addison MF, Dyck VA, Vreysen MJB (2010) Improved quality management to enhance the efficacy of the sterile insect technique for lepidopteran pests. J Appl Entomol 134:261-273

Simmons GS, McKemey AR, Morrison NI et al (2011) Field performance of a genetically engineered strain of pink bollworm. PLoS ONE 6:e24110. doi:10.1371/journal. pone. 0024110
Soopaya R, Stringer LD, Woods B, Stephens AEA, Butler RC, Lacey I, Kaur A, Suckling DM (2011) Radiation biology and inherited sterility of light brown apple moth (Lepidoptera: Tortricidae): developing a sterile insect release program. J Econ Entomol 104:1999-2008. doi:10.1603/ EC11049

Sørensen JG, Addison MF, Terblanche JS (2012) Mass-rearing of insects for pest management: challenges, synergies and advances from evolutionary physiology. Crop Protect 38:87-94

Sparks TC, Dripps JE, Watson GB, Paroonagian D (2012) Resistance and cross-resistance to the spinosyns-a review and analysis. Pestic Biochem Physiol 102:1-10. doi:10. 1016/j.pestbp.2011.11.004

Stephens AEA, Suckling DM, Burnip GM, Richmond J, Flynn A (2007) Field records of painted apple moth (Teia anartoides Walker: Lepidoptera: Lymantriidae) on plants and inanimate objects in Auckland, New Zealand. Aust J Entomol 46:152-159. doi:10.1111/j.1440-6055.2007. 00571.x

Stotter RL, Terblanche JS (2009) Low-temperature tolerance of false codling moth Thaumatotibia leucotreta (Meyrick) (Lepidoptera: Tortricidae) in South Africa. J Thermal Biol 34:320-325

Stringer LD, Sullivan NJ, Sullivan TES, Mitchell VJ, Manning LAM, Mas F, Hood-Nowotny RC, Suckling DM (2013) Attractiveness and competitiveness of irradiated light brown apple moths. Entomol Exp Appl 148:203-212. doi:10.1111/Eea.12096

Suckling DM (2015) Can we replace toxicants, achieve biosecurity, and generate market position with semiochemicals? Front Ecol Evol 3(17):1-7. doi:10.3389/fevo.2015.00017

Suckling DM, Charles J, Allan D, Chaggan A, Barrington A, Burnip GM, El-Sayed AM (2005) Performance of irradiated Teia anartoides (Lepidoptera: Lymantriidae) in urban Auckland, New Zealand. J Econ Entomol 98:1531-1538. doi:10.1603/0022-0493-98.5.1531

Suckling DM, Hackett JK, Chhagan A, Barrington A, El-Sayed AM (2006) Effect of irradiation on female painted apple moth Teia anartoides (Lep., Lymantriidae) sterility and attractiveness to males. J Appl Entomol 130:167-170

Suckling D, Barrington A, Chhagan A, Stephens A, Burnip G, Charles J, Wee S (2007) Eradication of the Australian painted apple moth Teia anartoides in New Zealand: trapping, inherited sterility, and male competitiveness. Area-wide control of insect pests. Springer, The Netherlands, pp 603-615

Suckling DM, Stringer LD, Mitchell VJ, Sullivan TE, Sullivan NJ, Simmons GS, Barrington AM, El-Sayed A (2011) Comparative fitness of irradiated light brown apple moths (Lepidoptera: Tortricidae) in a wind tunnel, hedgerow and vineyard. J Econ Entomol 104:1301

Suckling DM, Tobin PC, McCullough DG, Herms DA (2012) Combining tactics to exploit Allee effects for eradication of alien insect populations. J Econ Entomol 105:1-13. doi:10. 1603/EC11293

Suckling DM, Stringer LD, Baird DB, Butler RC, Sullivan TES, Lance DR, Simmons GS (2014a) Light brown apple moth (Epiphyas postvittana) (Lepidoptera: Tortricidae) colonization of California. Biol Invasions 16:1851-1864. doi:10.1007/s10530-013-0631-8 
Suckling DM, Stringer LD, Stephens AEA, Woods B, Williams DG, Baker G, El-Sayed AM (2014b) From integrated pest management to integrated pest eradication: technologies and future needs. Pest Manag Sci 70:179-189. doi:10. 1002/Ps.3670

Tabashnik BE, Morin S, Unnithan GC et al (2012) Sustained susceptibility of pink bollworm to Bt cotton in the United States. GM Crops Food 3:194-200

Thomas DD, Donnelly CA, Wood RJ, Alphey LS (2000) Insect population control using a dominant, repressible, lethal genetic system. Science 287:2474-2476. doi:10.1126/ science.287.5462.2474

Tobin PC, Kean JM, Suckling DM, McCullough DG, Herms DA, Stringer LD (2014) Determinants of successful arthropod eradication programs. Biol Invasions 16:410-414. doi:10.1007/s10530-013-0529-5

van Vuuren BJ, Potgieter L, van Vuuren JH (2015) The design of an agent-based model for simulating the population dynamics of Eldana saccharina (Lepidoptera: Pyralidae). Proc S Afr Sug Technol Ass 88:304-308

Vreysen MJB, Robinson AS, Hendrichs J (2007) Area-wide control of insect pests: from research to field implementation. Springer, Dordrecht
Vreysen MJB, Klassen W, Carpenter JE (2016) Overview of technological advances toward greater efficiency and efficacy in sterile insect-inherited sterility programs against moth pests. Fla Entomol 99:1-12. doi:10.1653/024.099. sp102

Wee SL, Suckling DM, Barrington AM (2011) Feasibility study on cytological sperm bundle assessment of F-1 progeny of irradiated male painted apple moth (Teia anartoides Walker; Lepidoptera: Lymantriidae) for the sterile insect technique. Aust J Entomol 50:269-275. doi:10.1111/j. 1440-6055.2011.00815.x

Witzgall P, Kirsch P, Cork A (2010) Sex pheromones and their impact on pest management. J Chem Ecol 36:80-100. doi:10.1007/s10886-009-9737-y

Woods B, McInnis D, Steiner E, Soopaya A, Lindsey J, Lacey I, Virdi A, Fogliani R (2016) Developing field cage tests to measure mating competitiveness of sterile light brown apple moths (Lepidoptera: Tortricidae) in Western Australia. Fla Entomol 99:138-145. doi:10.1653/024.099. sp117 